\title{
ASSESSMENT OF THERMAL TREATMENT FOR WINDROW DRYING PROCESS OF REFUSE-DERIVED FUEL (RDF): A CASE STUDY
}

\author{
Tamer M. Ismail ${ }^{1, \star}$, Kunio Yoshikawa ${ }^{2}$, Hisham Sherif ${ }^{3}$, Mohamed Salah ${ }^{4}$ and \\ Shaimaa Saeed ${ }^{3}$ \\ ${ }^{7}$ Mechanical Engineering Department, Suez Canal University, Ismailia, Egypt \\ ${ }^{2}$ School of Environment and Society, Tokyo Institute of Technology G5-8, 4259 Nagatsuta, Midori-Ku, Yokohama 226-8502, Japan \\ ${ }^{3}$ Chemical Engineering Department, Minya University, Minya, Egypt \\ ${ }^{4}$ Mechanical Engineering Department, Minya University, Minya, Egypt
}

Article Info:
Received:
7 November 2018
Revised:
24 February 2019
Accepted:
7 March 2019
Available online:
31 March 2019
Keywords:
Refuse-derived fuel (RDF)
Alternative fuel
Energy
Open air drying
Biological heating

\section{INTRODUCTION}

Municipal Solid Waste (MSW), that contain mixtures of paper, wood, green waste, food waste, plastics, leather, and rubber, can have energy characteristics similar to wood. Use of MSW as a fuel can be accomplished by burning the as-received material, known as mass burning, but processing is often required before it can be burned effectively. The purpose is to reduce size and remove valuable and non-combustible materials in order to be reclaimed and used as an alternative fuel for sustainable disposal and converted into green and clean energy. The ideal composition of RDF is high content in plastics, paper/cardboard, polymeric containers, textiles, wood and other organic matter [(Pohl, M. et al. 2008), (Garg, A., et al. 2007)]. Higher heating value is in fact associated with the aforementioned materials' content, and once these materials have a biogenic compound content of $40-80 \% \mathrm{w} / \mathrm{w}$, they become an interesting alternative fuel to accomplish the reduction of $\mathrm{CO} 2$ emissions. Moreover, meaningful advantages of RDF include its low production costs and significant calorific value Hilber, T., et al. (2007).

The drawbacks associated with these fuels are their heterogeneity, moisture and high ash, chlorine or sulphur content associated with energetic density, ignition, combustion and corrosion problems in boilers, Chatziaras, N. et al. (2016). Several benefits of using RDF in the cement industry blended with other fuels are expected, specifically ecological, with the reduction of non-renewable fossil fuels and the environmental impact that extraction would bring with it, thereby reducing greenhouse gas emissions. It should also be noteworthy that the wastes would otherwise have to be disposed of at waste disposal sites. The technical benefits enclose the destruction of organic material at high furnace temperatures and residence times, and the reduction of non-combustible parts of raw materials. The energy 
recovery from waste could be achieved by direct combustion, gasification or pyrolysis, with the first being more generally allocated. Nevertheless, palletization should be implemented once it is the potential way for mass and energy densification of these energetic materials. From an economic standpoint, in the cement industry, as fuel consumption decreases the production costs also decrease, Chatziaras, N. et al. (2016).

It is considered that a mechanical treatment (MT) system for a proper marketable RDF consists of at least two or three stages of shredding, at least two stages of magnetic separation for rejecting ferrous metals, at least one eddy-current separator for rejecting non-ferrous metals, and depending on the user requirements, at least two sieving stages, Sarc and Lorber (2013). Figure 1 shows a generic process flow and mass balance for a biological drying MBT. Once the necessary environmental and technological conditions are assured, and the objective of optimizing the RDF classification obtained, it is necessary to improve the economic value of the product, particularly through its LHV.

The main issue is related to the water (moisture) content existing in the RDF samples, which is a factor that causes a considerable discrepancy between the LHV and HHV Gallardo et al. (2015), or in other words, the minimum and expected heating value of the waste, and its maximum and achievable calorific value. By implementing procedures to correct this situation, an increase in the efficiency associated with the use of RDF would be obtained and the market would be promoted. Reinforcing the facts presented above, the waste flow from MBT has an average moisture of 40 $50 \%$, depending on factors such as the place of collection and seasonality, while the resulting RDF must have a $20 \%$ moisture at the most. The materials that contribute more to this water content are organic matter, paper/cardboard and textiles, Montejo, C. et al. (2011). Therefore, it is concluded that RDF drying is a necessary addition to be made to the process. Furthermore, it contributes to the improvement of their classification, which means this process becomes almost mandatory when the commercialization of the fuel is taken into account.

RDF drying could be divided into three groups: biodrying, where the energy source is the metabolic activity of the microorganisms that degrade the waste; thermal drying, which needs an external heat source, and open air drying in dry climates

Bio-drying could be defined as the process of reducing water content of the waste using the energy released from biodegradation as a heat source, and introducing air flow through the waste bed. This air flow is used to clear the excess water from the waste, since the moisture passes to the stream, then dilutes itself into the ambient air. Through this drying process, it is possible to increase the waste's lower heating value (LHV) from $30 \%$ to $40 \%$, Adani et al. (2002).

The main marketing target market is the cement industry, which uses RDF as co-fuel to heat kilns, given the fuel specificities, the combustion characteristics and the product itself. However, for RDF to be sold to cement factories and used in their kilns, the particle size must not exceed 10 $\mathrm{mm}$, as this is an important factor for the burning process. Drying technology generally reduces the MC of a matrix by heat application, causing water to evaporate into the air phase vapor, and produce dried outputs of desired characteristics. In addition to the cement industry, other energy-intensive industries could be RDF marketing targets, as done in Germany, where RDF is used in co-combustion systems in these types of facilities. RDF drying possibilities could be divided into two main groups, which differ prima-

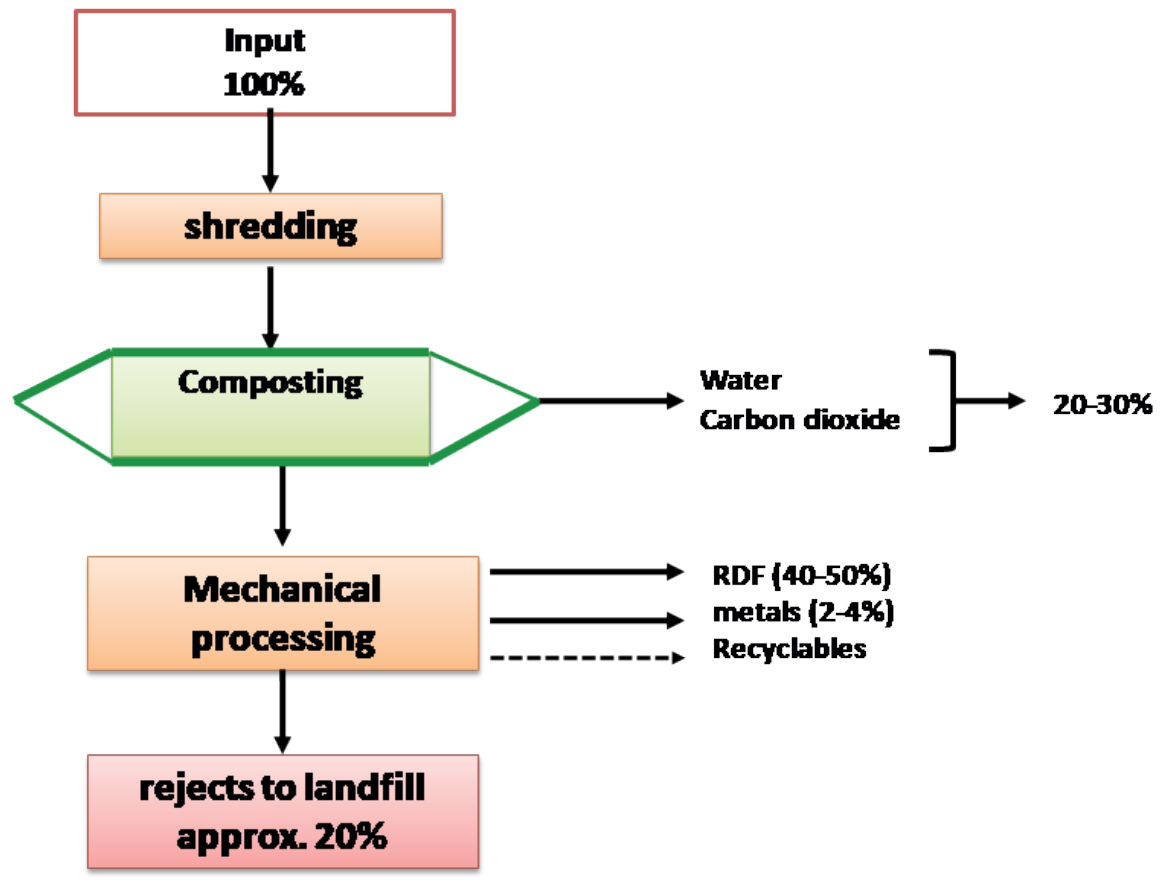

FIGURE 1: The figure shows a generic process flow and mass balance for a biological drying MBT. 
rily in the energy source used: bio-drying, where the energy source is the metabolic activity of the microorganisms that degrade the waste; and thermal drying, where there is a power consumption from an external source. In addition to water vapor and potential exhaust gases produced by drying processes, low temperature drying processes such as those studied produce volatile organic compounds.

This issue was not considered in the technological nor the economic analysis, given the possibility of adding a treatment phase to the process. Bio-drying can be defined as a process for reducing the water content by convective evaporation, which uses the energy released by the biodegradation of the waste as a heat source, and introduces an air flow. The introduced air flow is responsible for transporting the excess water in the waste, since the moisture passes from this to the stream and then it dilutes itself into the ambient air. Bio-drying processes have the objective of reducing moisture content, differentiating from composting processes by preserving most of the existing biomass in the waste matrix, as well as its calorific value. Through this drying process, it is possible to increase the waste's LHV from $30 \%$ to $40 \%$, Adani et al. (2002).

According to Rada and Ragazzi (2014), bio-drying should only be considered when the food (or organic) waste fraction is equal to or greater than $50 \%$ of the sample in study, while a limiting factor could be considered when this fraction is equal to or less than $30 \%$. However, all samples that follow these guidelines and that are subjected to biodrying demonstrate a significant improvement in their LHV [Rada and Ragazzi (2014), Ayman Elnaas, et al., (2015), Larsen, Ib. (2015)]. Regarding the moisture content, bio-drying proves to be ineffective in obtaining an average moisture content below $20 \%$. In specific cases, such as for obtaining an RDF with moisture content less than $20 \%$, this process must be reinforced with thermal drying. Therefore, the objective of this research is to experimentally assess open air drying of RDF, when assisted with a turning machine.

\subsection{Nomenclature}

$\mathrm{a}_{\mathrm{s}}=$ specific area $\mathrm{m}^{2} / \mathrm{m}^{3}$

$\mathrm{C}_{\mathrm{RDF}}=$ specific heat of RDFkJ $/ \mathrm{kg} \cdot \mathrm{K}$

$\mathrm{C}_{\mathrm{W}}=$ specific heat of waterkJ $/ \mathrm{kg} . \mathrm{K}$

$\mathrm{k}_{\mathrm{m}} \mathrm{a}_{\mathrm{s}}=$ mass transfer coefficient area product $\mathrm{kga} /\left(\mathrm{s} \mathrm{m}^{3}\right)$

$\mathrm{m}_{\mathrm{ev}}=$ water vapor removed from RDF $\mathrm{kg}_{\mathrm{w}}$

$\mathrm{m}_{\mathrm{ds}}=$ mass of dry solid $\mathrm{kg}$

$\mathrm{Q}_{\mathrm{RDF}, \mathrm{g}}=$ total bioheat during drying $\mathrm{kJ}$

$\mathrm{RH}_{\mathrm{amb}}=$ ambient relative humidity \%

$\mathrm{T}_{\mathrm{RDF}}=\mathrm{RDF}$ temperature ${ }^{\circ} \mathrm{C}$

$\mathrm{T}_{\mathrm{m} / \mathrm{c}}=$ turning machine runing time $\mathrm{h}$

$\mathrm{T}_{\text {amb }}=$ ambient air temperature ${ }^{\circ} \mathrm{C}$

$\mathrm{V}=$ volume of the row $\mathrm{m}^{3}$

$\mathrm{X}=$ moisture content $\%$

$\Delta \mathrm{T}_{\mathrm{RDF}}=\mathrm{T}_{\mathrm{RDF}}-\mathrm{T}_{\mathrm{amb}}{ }^{\circ} \mathrm{C}$

$\Delta \mathrm{x}=$ moisture content difference after one stroke of turning $\mathrm{m} / \mathrm{c}$

$\tau_{m / c}=$ Time of one machine stroke $s$

$\omega^{*}=$ specific humidity at saturation corresponding to RDF temperature $\mathrm{kg}_{\mathrm{w}} / \mathrm{kg}_{\mathrm{da}}$

$\omega_{\text {amb }}=$ ambient air specific humidity $\mathrm{kg}_{\mathrm{w}} / \mathrm{kg}_{\mathrm{da}}$

\section{MATERIAL AND METHODS}

The experimental work was done in a facility located in 15 May City, South Cairo, Egypt. It belongs to ECARU Company, working in municipal solid waste treatment. This facility receives 1500 tons of municipal solid waste per day. A daily output of about 300 dry RDF is distributed to nearby cement factories. The open air drying area is a $100 \mathrm{~m} 100 \mathrm{~m}$ concrete slab. A matrix of rows is constructed parallel to each other, with a space in between to give enough space for the turning machine to do the turning process required for drying. The turning machine works in many rows simultaneously to get the required output. In order to improve the performance of this drying process, experimental work was carried out to get the data required, especially in regions with bad climatic conditions. The following quantities were measured: the hourly data of ambient temperature and relative humidity, the moisture content of RDF after each working stroke of the turning machine, the temperature of RDF and the specific fuel consumption.

\subsection{The climate data of the site}

The measured ambient temperature and relative humidity were taken on the 5th of December, the first day of experiment. It doesn't change too much within the period of the experimental work. The measured values are shown in Figure 2. Time was measured starting midnight.

\section{RESULTS AND DISCUSIONS}

\subsection{Preliminary investigation on the Driving Force for open air drying}

The driving force curves $\Delta \omega=\omega^{*}$ - $\omega$ versus time for each incremental rise of RDF temperature is shown in Figure 3. The figure shows that the driving force for water evaporation decreases starting midnight till it reaches its minimum value at $7 \mathrm{AM}$, at which point it starts to increase till it reaches a maximum value at $1 \mathrm{PM}$, then it starts to decrease again. If the turning machine is to work only 8 hours per day, the best period of operation is from $10 \mathrm{AM}$ to $6 \mathrm{PM}$. Also, it can be seen that at any given moment, the driving force increases exponentially with increasing RDF temperature. This is due to the vapor pressure at saturation, which has an exponential function with the temperature. The driving force for evaporation increases with increasing RDF temperature, but the convective heat loss from the hot RDF to the cold ambient air also increases at the expense of evaporation. If the turning machine works at night, external heating is required to increase the temperature of RDF at least $15^{\circ} \mathrm{C}$ higher than the ambient air to get suitable driving force for evaporation.

\subsection{RDF Temperature}

RDF temperatures were measured at the core of the row after each stroke of the turning machine. The average ambient temperature and the relative humidity during the operation of the turning machine were nearly constant at $21^{\circ} \mathrm{C}$ and $65 \%$, respectively. Figure 4 shows this temperature versus the running time of the turning machine. There is a time lapse of about 17 hours between the end of one day 


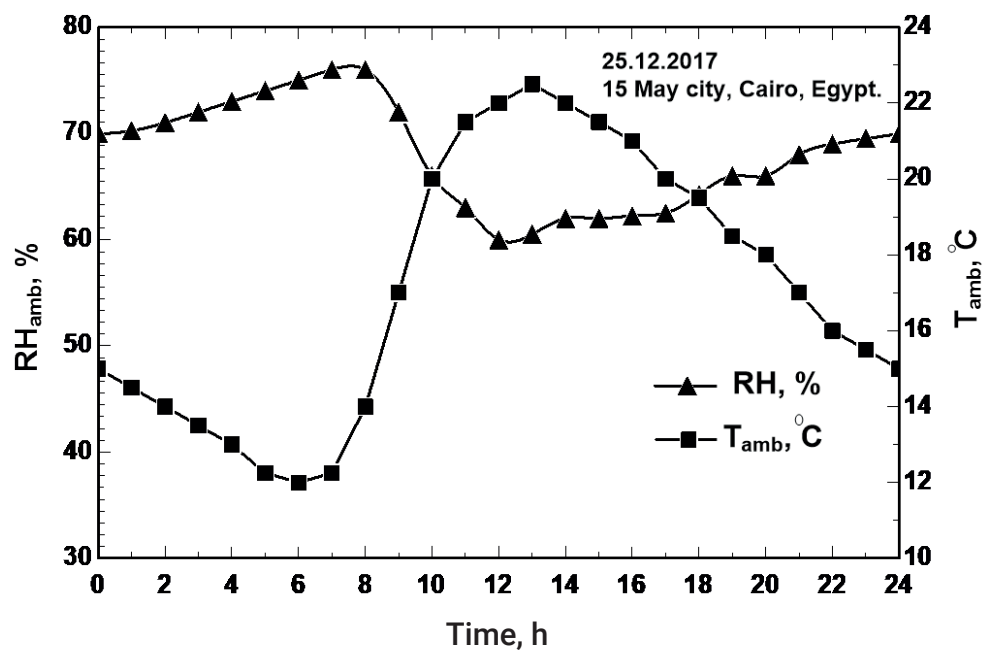

FIGURE 2: Ambient temperature and relative humidity versus time.

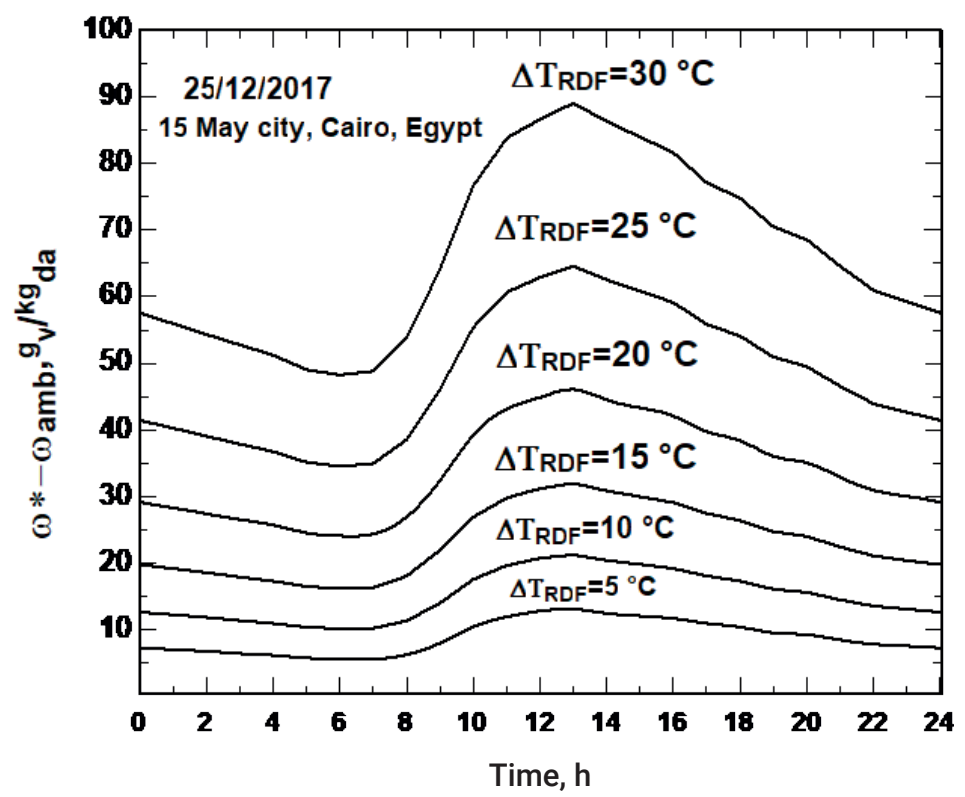

FIGURE 3: Driving force versus time for each incremental temperature rise of RDF.

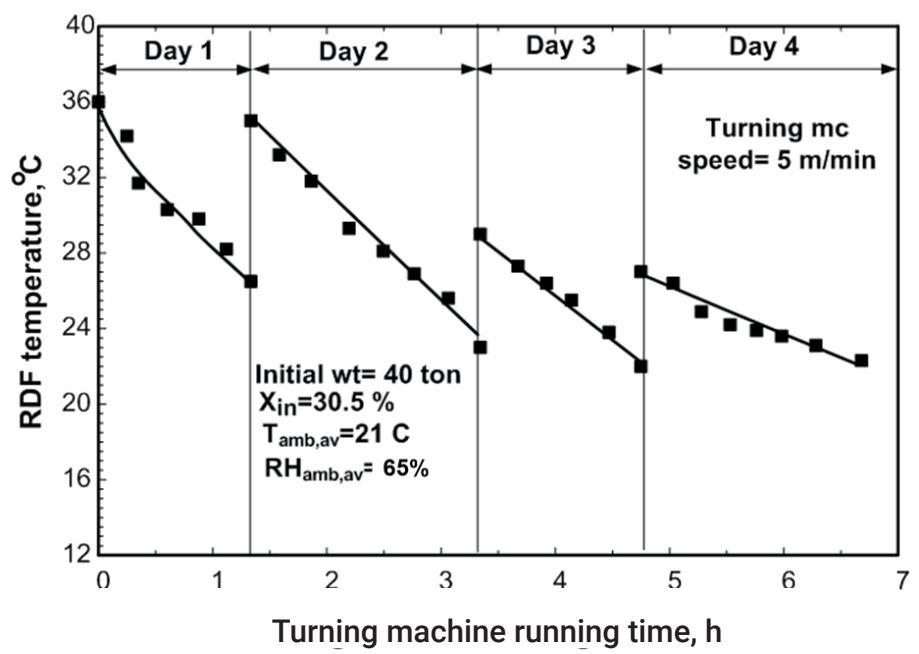

FIGURE 4: RDF temperature versus turning machine running time, $\mathrm{h}$. 
and the next (doesn't appear on the curve). In this period, the temperature of the RDF increased due to the heat generated by the biological activity. Twenty-five strokes over four consecutive days were required for the drying of the 40-ton initial RDF wet product. The initial temperature of the RDF was $36^{\circ} \mathrm{C}$, which is $15^{\circ} \mathrm{C}$ higher than the ambient temperature. This temperature decreases linearly with the running time of the machine. The temperature rise during the periods at which the machine is off is mainly biological heat. The summation of this heat during the drying time was calculated from temperature rise of the RDF as follows:

$\mathrm{Q}_{\mathrm{RDF}, \mathrm{g}}=\sum_{\mathrm{i}=1}^{4} \mathrm{~m}_{\mathrm{RDF}, \mathrm{ds}} \times\left(\mathrm{C}_{\mathrm{RDF}}+\mathrm{X}_{\mathrm{i}} \cdot \mathrm{C}_{\mathrm{W}}\right) \times\left(\mathrm{T}_{\mathrm{RDF}, \mathrm{i}}-\mathrm{T}_{\mathrm{RDF}, \mathrm{i}-1}\right)$

The results obtained from this equation showed that the total heat generated in the RDF was $22.312 \mathrm{kWh} /$ ton wet product; $9.818 \mathrm{kWh} /$ ton on the first day, 6.027 on the second, 3.573 on the third, and 2.894 on the fourth. Figure 4 shows that the RDF behaves as a battery, emptying its charge during the operation of the turning machine, and then recharging during night, but the level of the charge decreases from day to day. This behavior suggests using external heating to recharge the RDF when its temperature falls to a certain limit; auxiliary heat with automatic control could optimize this process.

\subsection{RDF Moisture Content}

Figure 5 shows the typical curve of RDF moisture content versus the running time of the turning machine on the row. The drying takes place in the open air, without covering overnight. The row was $70 \mathrm{~m}$ long, $2 \mathrm{~m}$ wide and 3 $\mathrm{m}$ high. The initial mass of the RDF was 40 tons, with an initial moisture content of $30.5 \%$. The linear speed of the turning machine was $5 \mathrm{~m} / \mathrm{min}$. From the figure, it is clear that 25 strokes of the turning machine were done to reach a $14.5 \%$ moisture content. These strokes were spread out over 4 consecutive days, to give a chance for bio-heating by the action of aerobic bacteria. The rate of decrease in moisture content per machine-running hour was $2.42 \%$. The rate of water evaporation per ton of wet product was $21.6 \mathrm{~kg} / \mathrm{ton} / \mathrm{machine}$ hour. The figure shows that during the night between two consecutive days, the moisture content will increase on account of the dew that falls over the RDF.

The figure also shows that the increase in moisture content from the dew is lower at higher values of RDF moisture content, and it increases with the decrease in moisture content at the end of drying. This can be attributed to the higher heat capacity at higher moisture content. When the heat capacity is high, it is difficult to cool the RDF to the dew point temperature. 6.7 hours of turning machine operation were required to decrease the moisture content of 40 tons of RDF from 0.3 to 0.14 . The dashed curve is the expected curve if the rows were covered overnight. If the RDF was covered overnight, a $12 \%$ decrease in drying time is expected.

Figure 6 shows the variation of RDF moisture content versus the running time of the turning machine. In this experiment, the turning machine took 13 hours to decre- ase the moisture content from $24 \%$ to $14 \%$, which means $0.77 \%$ per hour. This figure shows the effect of lowering the speed of the turning machine from $5 \mathrm{~m} / \mathrm{min}$ to $3 \mathrm{~m} / \mathrm{min}$. The result was contrary to our expectation of improving the performance by increasing the residence time of turning on the row. The bad performance may be attributed to the evacuation of the RDF in front of the turning drum, thereby decreasing turning efficiency. Therefore, the speed of the turning machine was increased to avoid this problem.

Figure 7 shows the moisture content of RDF versus the running time of the turning machine. The conditions of this experiment were the same as those of the curve in Figure 5, except that 20 turns were done with a loader during turning machine operation. The drying time deceased from 6.7 to 5.6 hours.

Figure 8 shows the moisture content versus the running time of the machine, in the case of adding more turning with a loader and for two different rows of RDF. Although the turning increased with the loader, it seems from the figure that the decrease in moisture content is not affected by these changes during the first 3 hours of the drying process. However, the changes do become clear toward the end of the drying process. This can be attributed to the improvement in volumetric mass transfer coefficient with time, which will be discussed in the next section. It is clear that the data followed a certain trend. This trend was obtained by curve fitting. The moisture content versus time within the conditions mentioned is given by:

$\mathrm{X}[\%]=30.094-1.9 \mathrm{~T}_{\mathrm{m} / \mathrm{c}}+0.181 \mathrm{~T}_{\mathrm{m} / \mathrm{c}}^{2}-0.037 \mathrm{~T}_{\mathrm{m} / \mathrm{c}}^{3}$

\subsection{The mass transfer coefficient}

In order to explain the trend in Figure 8, the mass transfer coefficient was calculated from the measured data. It is difficult to calculate the area of mass transfer between RDF and air during turning machine running time. Therefore, it is difficult to calculate the mass transfer coefficient separately. The product of the mass transfer coefficient $\left(k_{m}\right)$ and the specific area per unit volume $\left(a_{s}\right)$ of the RDF was calculated by the data taken from the experiments. It is called the volumetric mass transfer coefficient $\left(k_{m} a_{s}\right)$, and is expressed in the following equations:

$m_{\mathrm{ev}}=m_{\mathrm{ds}}(\Delta x)$

$\mathrm{m}_{\mathrm{ev}}=\mathrm{k}_{\mathrm{m}} a_{\mathrm{s}} \mathrm{V}\left(\omega^{*}-\omega_{\mathrm{amb}}\right) \tau_{\mathrm{m} / \mathrm{c}}$

Figure 9 shows the values of kmas versus the moisture content of RDF. The solid curve is the trend of the data. The volumetric mass transfer coefficient $\mathrm{k}_{\mathrm{m}} \mathrm{a}_{\mathrm{s}}$ is about 0.04 $\mathrm{kg} / \mathrm{m}^{3}$ at moisture content $30 \%$. It increases exponentially with decreasing moisture content till it reaches a maximum value of 0.28 , then it decreases with a further decrease in moisture content. This trend will be attributed to the following; at higher values of moisture content, the efficiency of the turning machine is low. Therefore, the interfacial area of mass transfer will be small.

As the moisture content decreases, the RDF will become more fluffy, the turning efficiency will improve, and the area will increase, consequenly the product will increase to a maximum value. It is known that the mass transfer coeffi- 


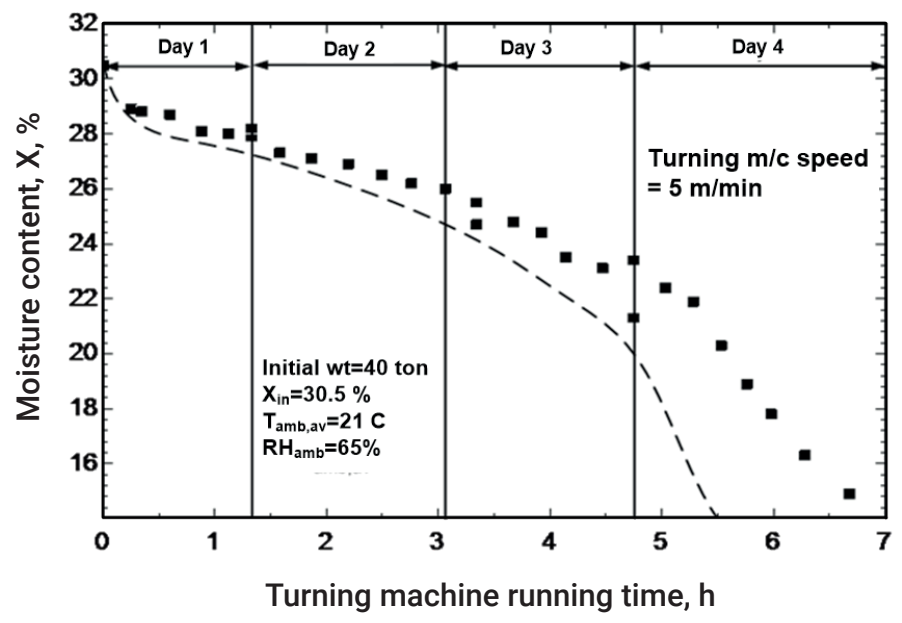

FIGURE 5: Moisture content versus turning machine running time, $\mathrm{h}$.

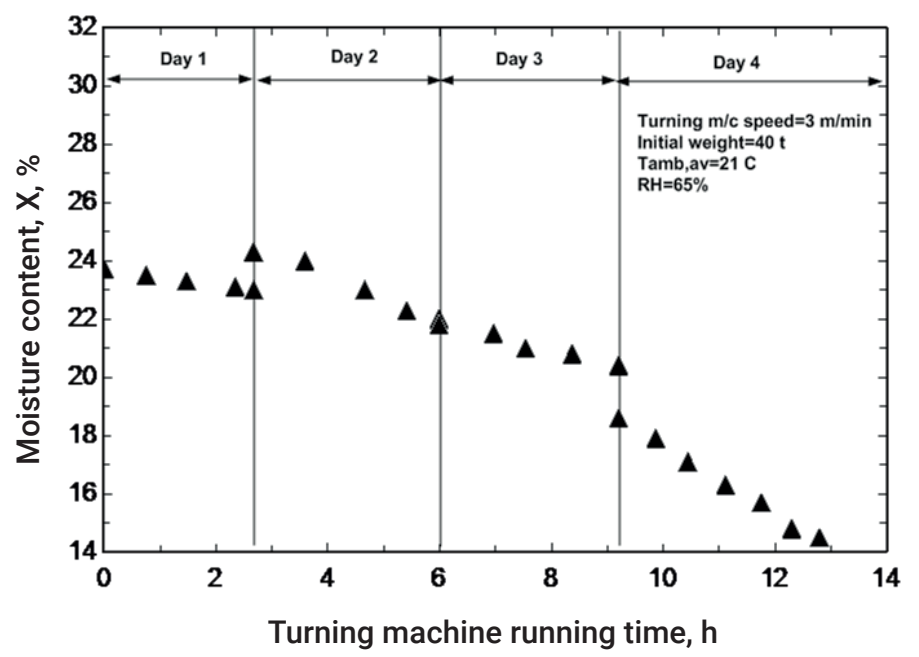

FIGURE 6: shows the variation of RDF moisture content versus running time of the turning machine.

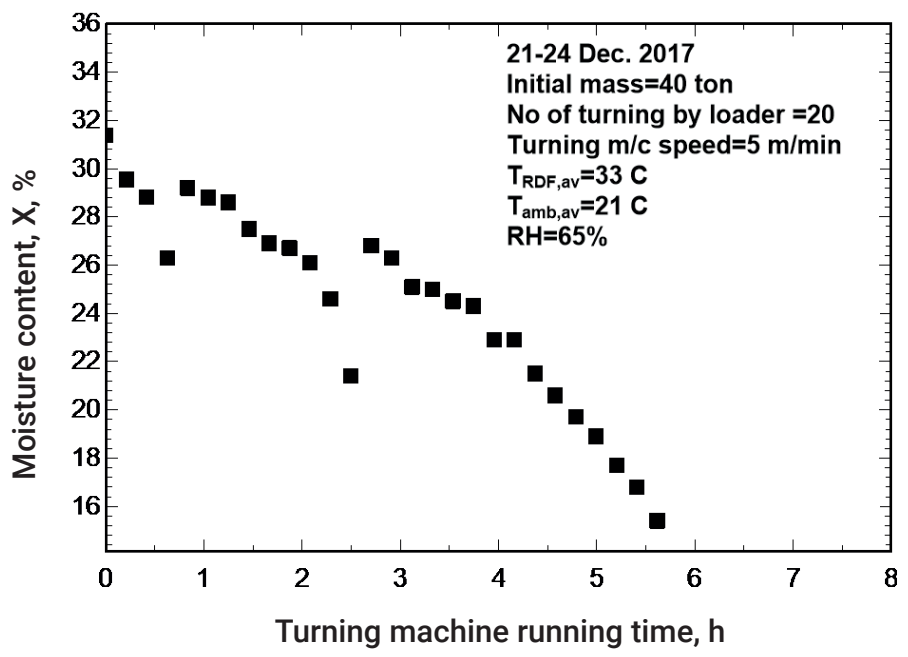

FIGURE 7: The figure shows the moisture content of RDF versus running time of the turning machine.

cient will decrease in the falling rate period. Therefore, there are two effects contradicting each other now, the area of mass transfer, $a_{s}$, increases with decreasing moisture content, and at the same time the mass transfer coefficient, $\mathrm{k}_{\mathrm{m}}$, decreases in the falling rate period. When the decrease in mass transfer coefficient becomes higher than the increase in area, the product starts to fall after the maximum value. In any case, the fact that the volumetric mass transfer 


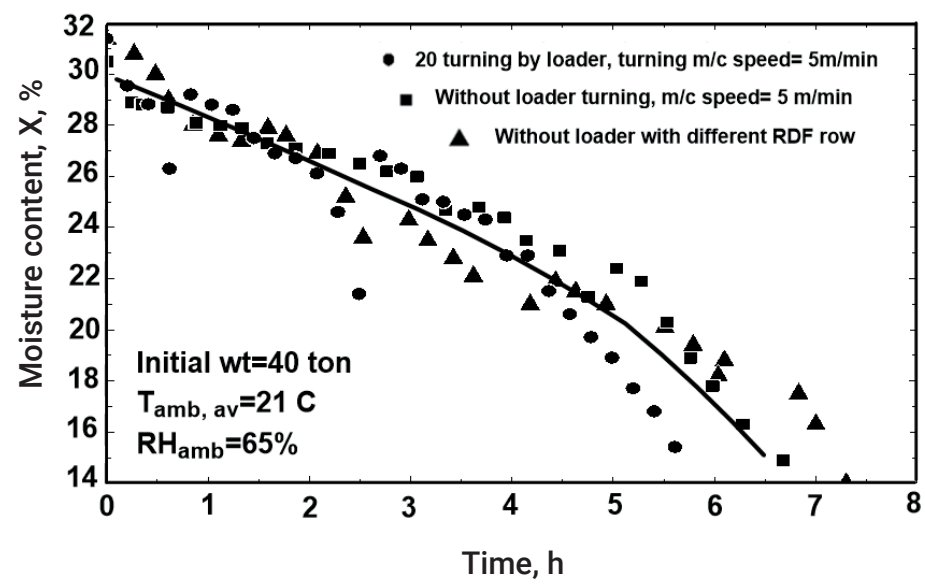

FIGURE 8: Moisture content versus running time of turning machine, for Different turning and different rows of RDF.

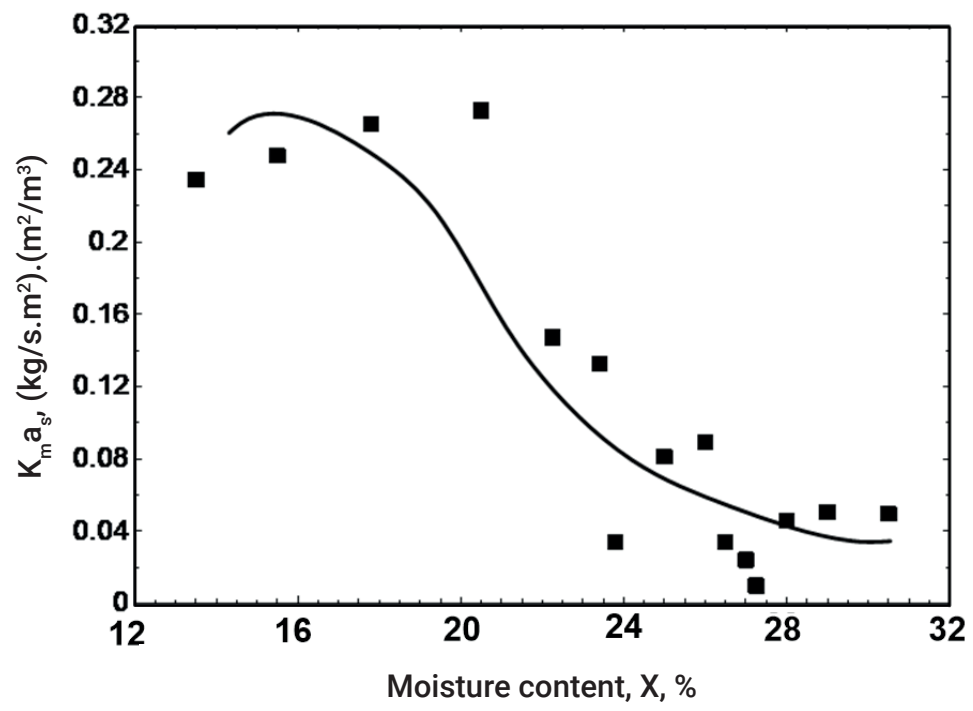

FIGURE 9: Mass transfer coefficient area product versus moisture content.

coefficient starts to fall just at the final required moisture content, is quite favorable.

\section{CONCLUSIONS}

Experimental work was carried out in an industrial scale open air drying facility, assisted with a turning machine. It introduced data that helped in improving the performance of this drying process.

The drying time for decreasing the moisture content of RDF from $30.5 \%$ to $16 \%$ was 6 hours, at a turning machine speed of $5 \mathrm{~m} / \mathrm{min}$ and winter weather conditions. The speed of the turning machine must be higher than $3 \mathrm{~m} / \mathrm{min}$ to avoid the evacuation of the RDF in front of the turning drum.

Although the drying needs 6 hours of turning machine operation, this time must be distributed over 4 days to benefit from the bio-heating process. The effect of this heating process on the temperature distribution of RDF during the drying process was illustrated in this study. The bioheating energy was $22.3 \mathrm{kWh} /$ ton (wet product).

The volumetric mass transfer coefficients increased about seven-fold during the drying process. The coefficient was $0.04,0.017$ and $0.24 \mathrm{~kg} / \mathrm{m}^{3}$ at moisture contents $30 \%$, $20 \%$ and $15 \%$, respectively. The rate of water evaporation was $21.6 \mathrm{~kg} / \mathrm{ton}(\mathrm{wp}) / \mathrm{h}$. Turning machine drying is more efficient when the moisture content becomes less than $24 \%$. The data introduced are helpful for enhancing the drying process in bad weather conditions, and this will be our future work.

\section{AKNOWLED GEMENTS}

Many thanks to The ECARU Company, one of the biggest companies in the Middle East working in municipal solid waste treatment, for their technical guidance during the experimental work. Also, many thanks to all the collaborators for supporting us with the main feedstock.

\section{REFERENCES}

Adani, F., et al. 2002. The influence of biomass temperature on biostabilization-biodrying of municipal solid waste. Bioresource Technology 83(3):173-9 
Ayman Elnaas, Abdallah Nassour and Michael Nelles 2015 Markets for solid waste management in Arab countries, guidelines for co-processing fuels and raw materials in cement manufacturing, cement sustainable institute initiative (CSI) WBCSD.

Chatziaras, N., Psomopoulos, C. S., Themelis, N. J. 2016. Use of waste derived fuels in cement industry: a review, Management of Environmental Quality, Vol. 27 Iss 2 pp. 178 - 193.

Cristina Montejo, Carlos Costa, Pedro Ramos, Maria Del Carmen Marquez 2011. Analysis and comparison of municipal solid waste and reject fraction as fuels for incineration plants. Applied Thermal Engineering, vol. 31 Issue 13 pp. 2135-2140.

Evangelou, A., Gerassimidou, S., Mavrakis, N., Komilis, D., 2016. Monitoring theperformances of a real scale municipal solid waste composting and a biodryingfacility using respiration activity indices. Environ. Monit. Assess. 188, 302.

Gallardoa A, Carlosb M, Boveac MD, Colomerd FJ, Albarrane F, 2015. Analysis of refuse-derived fuel from the municipal solid waste reject fraction and its compliance with quality standards, $\mathrm{pp}$. $1-15$

Garg, A., Smith, R., Hill, D., Simms, N., \& Pollard, S. 2007. Wastes as Co-Fuels: The Policy Framework for Solid Recovered Fuel (SRF) in Europe, with UK Implications Environmental Sciente \& teccnology, Vol. 41, pp. $4868-4874$.
Hilber, T., Thorwarth, H., Stack-Lara, V., Schneider, M., Maier, J. and Scheffknecht, G. 2007. Fate of mercury and chlorine during SRF co-combustion,Vol. 86, Issues 12-13, pp. 1935-1946

Larsen, Ib. 2015. RDF as an alternative fuel for the cement industry ina south East Asian context, stakeholder workshop "mitigation efforts in the cement and steel industry", Malaysia.

Negoi, R.M., Ragazzi, M., Apostol, T., Rada, E.C., Marculescu, C., 2009. Biodrying of Romanian municipal solid waste: an analysis of its viability. U.P.B. Sci. Bull., Ser.C 71, (4).

Pohl, M., Gebauer, K., \& Beckmann, M. 2008. Characterisation of Refuse Derived Fuels in view of the Fuel Technical Properties. Infub - 8th European Conference on Industrial Furnaces and Boilers, VILAMOURA-ALGARVE, PORTUGAL, 25-28 MARCH 2008

Psaltis, P.,Komilis, D. (2019). Environmental and economic assessment of the use of biodrying before thermal treatment of municipal solid waste.Waste Management. 83:95-103

Rada EC, Ragazzi M.(2014). Selective collection as a pretreatment for indirect solid recovered fuel generation. Waste Management; 34(2):291-297

Sarc, R. and K. E. Lorber 2013. Production, quality and quality assurance of Refuse Derived Fuels (RDFs),Waste Management,Vol.33, Issue 9, pp. 1825-1834

Tambone, F., Scaglia, B., Scotti, S., Adani, F., 2011. Effects of biodrying process onmunicipal solid waste properties. Bioresour. Technol. $102,7443-7450$ 